\title{
Using a Transactional Model and Thematic Analysis to Evaluate a Minority Male Student Success Initiative to Improve Participants' Campus Experience and Retention
}

\author{
Kathryn Todd Bliss ${ }^{1}$, Richard Mensah ${ }^{1}$, Kelly D. Bradley (i) 1,*, \\ Alexis Rodgers ${ }^{1}$, Falynn Thompson ${ }^{1}$
}

\author{
${ }^{1}$ University of Kentucky, College of Education, Department of Educational Policy Studies \& Evaluation
}

\author{
ARTICLE HISTORY \\ Received: 18 May 2018 \\ Revised: 29 September 2018 \\ Accepted: 19 October 2018
}

\section{KEYWORDS}

Evaluation,

Minority students,

Higher education,

Transactional model

\begin{abstract}
While the national discourse about the call for increased effort to help strengthen retention and graduation rates among minority college students seems to be losing its vigor, concerned citizens continue to find other means to sustain the momentum. Similarly, the office for institutional diversity at a public southeastern university established a minority male student success initiative in 2010 to help improve the educational experience of its members. The evaluators' objectives for this transactional, formative, and qualitative evaluation were to understand this initiative from the different vantage points of its stakeholders, and to determine if they were satisfied thus far with its trajectory. The evaluators found that while some stakeholders held similar perspectives, others differed in their views on the initiative's goal(s). The majority, however, expressed satisfaction with the initiative's direction at the time of the evaluation.
\end{abstract}

\section{INTRODUCTION}

The difficulties that African American and Latino male populations face at the higher education level in the United States are ongoing national issues, and deserve special attention and support. Low retention and graduation rates are some of the leading issues. The present research was to examine the efforts of a public predominantly white southeastern university (PSEU) in its attempt to address the challenges its minority male students face in their campus life. The results shed light on methods to help address these issues on similar campuses.

In 2010, the administrative leadership of a PSEU authorized its head administrator of the Office for Institutional Diversity (OID) to commission a faculty member to lead efforts to establish a research-based initiative to improve the on-campus experience of its African American male students. Data from the PSEU's Office for Institutional Research had indicated that African American men performed lowest among all racial and gender groups. The initial general goal 
was to focus efforts on this particular group of students to provide a place for them to discuss their campus experiences.

The leadership of this newly founded initiative established a research goal to uncover the concerns of the students and, to some extent, help the students expel any harmful assumptions they might have about campus experiences. A second research goal was to then publish any research findings for individuals on the PSEU's campus who were interested in helping minority students, as well as for other higher education institutions whose minority male students struggled with similar issues. The research results would, thus, not only benefit this PSEU, but they could also assist other institutions with similar initiatives. The PSEU recognized the value of African American men leading such an effort, given their parallel personal experiences to those of the students served by this program. The leadership named the undertaking the Black Male Initiative and an African American assistant professor was commissioned to direct it. In 2012, the leadership decided to add the Latino population to this effort because these students often experience similar difficulties as African American students. As a result, the leadership officially renamed this effort the Minority Male Student Success Initiative-henceforth referred to as the Initiative.

Most of the Black male initiatives (BMI) on higher educational campuses have very similar goals - increasing matriculation, retention, and graduation rates among male students of color. They have some form of mentoring programs that seek to shepherd students from matriculation to graduation. However, while some are specifically meant for Black male students (Office of Diversity and Inclusion-UCO, 2014), others include all underrepresented student groups (CUNY Black Male Initiative, CUNY BMI, 2005). Furthermore, some BMIs are established statewide (University System of Georgia's African-American Male Initiative, AAMI, 2002), while others are institution-specific, like the CUNY BMI. The Initiative is institution-specific but employs a modified version of the AAMI and CUNY BMI models, albeit AAMI is statewide. The AAMI and CUNY BMI have pre-college community outreach and recruitment components in their programs, but the Initiative does not.

The leadership established a smaller group (21 students) from the Initiative that would meet monthly to engage in focus groups. This group also participated in an on-campus faculty-student mentoring program. The name of this 21-member subgroup is the Male Scholars Program (henceforth called the Program - the Program director also serves as the Initiative faculty director). The leadership of the Initiative hoped to use the Program's activities to track and measure the students' experiences for the benefit of the students and for research purposes. The Program director also intended for these 21 students to eventually engage in a community service project, which would include three mini-projects: an after-school program, a fifth-grade lunch program, and a high school mentoring program. The leadership was unable to launch this community service aspect due to insufficient resources, but the underlying purpose was for these young men to put into practice the mentoring they received on campus with school children in their respective community of residence.

In order to determine if the expectations of the various stakeholders were congruent with the goals of the Initiative, the overarching question the evaluators sought to address in this formative evaluation was whether some stakeholders viewed the Initiative the same or differently from others (House, 1978, p. 12). The initial perception of the evaluators was that the Initiative and the Program were separate but associated efforts, thus they outlined two objectives they intended to achieve in this evaluation:

1. To understand the Initiative and the Program from the different vantage points of their stakeholders.

2. To determine if the student participants, administrators, and volunteer mentors were satisfied thus far with the Initiative and the Program. 
To achieve the first objective, the evaluators needed to understand how the stakeholders perceived the goals of the Initiative and the Program. Through this understanding and the articulation of different vantage points, the evaluators believed it may help clarify how to describe these efforts as entities for their own benefit and in relation to similar efforts. The second objective would help the evaluators to take into account and to allow for the reporting of whether or not the student participants' initial expectations were met, administrators felt that the efforts were moving in the intended direction, and if volunteer mentors felt that they were part of a worthwhile effort at the university.

The evaluators employed a transactional evaluation model (House, 1978; Patton, 2002; Rippey, 1973; Stake, 1973) in order to understand the various viewpoints of stakeholders invested in the Initiative and the Program. The evaluators believed that this approach would offer a thorough account of a program that was in a developmental stage. They also felt that it would help them to understand and present the stakeholders' perspectives on the goal(s) of the Initiative and its programmatic activities. And finally, using the transactional evaluation model would help the evaluators determine whether Program participants were satisfied or dissatisfied with the given endeavors. This is because using the transactional model allows the evaluators to give voice to the individuals (House, 1978; Patton, 2002) affected by these ongoing national issues on the PSEU campus examined in the present research.

In line with the two outlined objectives, the researchers of this formative evaluation aimed: to understand the different perspectives of the student participants, administrators, and volunteer mentors of the Initiative and its associated Program; and to determine if these stakeholders were satisfied with the efforts' progress and direction at the point of the evaluation. The researchers hoped that by answering such questions and meeting these objectives, they could help demonstrate to the stakeholders if the efforts were effectively supporting the African American and Latino student participants in their higher education endeavors, or at least making progress toward fulfillment of this purpose. For the PSEU administrators of this Initiative, progress toward this purpose could be a contribution toward addressing this national issue.

\subsection{Literature Review}

\subsubsection{On-Campus Diversity}

The population of the United States may be described as racially and ethnically diverse, but higher education institutions do not reflect this diverse composition. For example, statistics drawn from the PSEU for fall 2012 for the African American Latino undergraduate student population mirrored that of the state in which the PSEU is situated, yet those numbers did not reflect the groups' representations on the campus (PSEU Public Relations Representative, 2012). In addition to promoting inclusion, racial diversity on higher education campuses has been shown to serve educational purposes and benefits (Gurin, Dey, Hurtado, \& Gurin, 2002). Not only does diversity provide a feeling of community and fellowship for minority students on predominantly white institution (PWI) campuses, it also enhances the overall campus experience for all races and ethnicities (Spitzberg \& Thorndike, 1992). The feeling of community and fellowship encouraged the PSEU to create the Initiative, with the hope of enriching the campus experience of the student participants.

\subsubsection{Retention}

Colleges and universities might be providing greater access to higher education for minority students, but they still grapple with student retention (Seidman, 2005). Among the myriad explanations cited for this difficulty is students' unpreparedness prior to admission (Redden, 2009). Redden (2009) also adds that the lack of a supportive atmosphere, especially for minorities, undermines enrollment efforts. Kim and Conrad (2006) have found that one of the best approaches for improving retention rates of African American men is encouraging these 
students to become involved in "academically engaging interactions" such as assisting faculty members with research projects (p. 420). Lascher (2008) suggests that, "there is strong reason to think that the major factors [of retention] operate similarly across ethnic groups" (p. 12). The PSEU believed that the Initiative could create the needed supportive atmosphere by, for example, linking minority students with mentors with similar cultural backgrounds. It perceived faculty-student interactions as very important in helping the students to stay in school to finish.

\subsubsection{Experiences of Minority Students at Predominantly White Institutions}

The negative school experiences of African American and Latino male students at many educational levels, such as high school (Ford, 2012; Roderick, 2003) and college (McGee \& Martin, 2011; Strayhorn, 2010), have been empirically investigated. Lewis, Oliver and Burris (2011) suggest that the alarming rate of attrition and low enrollment among minorities could be due to reasons such as...

... disproportionately high school dropout rates for black [sic] male students; stressful economic circumstances for black families; the influence of popular culture, particularly the influence of hip-hop music and culture on black males; the high incidence of black males entering the military; the availability of employment after high schools [sic]; disproportionately higher levels of incarceration among black males; high rates of homicide among black males; and fear, distrust, and unfamiliarity with college environments. (p. 4)

Lewis et al. (2011) also outline student discussions on feelings of a lack of belonging, worthlessness, perceived racism, and lack of support from faculty, administrators, and students. One student explained his experience with racism...

Everyone has their story of randomly being called a nigger on campus. And I was talking to some guys the other day at the [Drexel Center] and they were like, "Well, it wouldn't be a normal semester for me if I didn't get called 'nigger' at least once." I'm like, "Really?" And, I mean, it recently happened to me and I'm just at the point where.... It happened last year-whatever-I couldn't worry about it. I guess in the initial state of it, you're like, "OK, well, I wonder what..." because it was so random. It's like I wonder what they're thinking about me; I wonder how you really feel. I mean, after a while, it starts to go away; but at this point it's still rampant in my... I mean it's hard to get past that. You know you have to go to class, and you go to class, you do your best and everything, but still in your head, it's like, it's, it's hard to get past that. (Lewis et al., 2011, p. 14)

Other research studies capture the experiences of individuals from differing racial and ethnic backgrounds who are students at a PWI. Jones, Castellanos and Cole (2002) interviewed students from several minority groups (African American, Latino, American Indian, and Asian American) and a number of them reported experiences of overt racism and alienation. The students believed that school administrators were unable to fulfill their promise of taking proactive steps to correct the situation. The PSEU in this research believed such negative experiences are some of the leading forces that impact enrollment, retention, and graduation of minority students (Jackson, 2012; Lewis, Oliver, \& Burris, 2011; Strayhorn, 2010), and that neglecting to make efforts to promote belongingness and self-worth among racial minorities is to let the status quo remain. The administrators wanted to use the Initiative to bring some changes to the situation.

\subsubsection{Mentoring}

To a large extent, recruiting students to occupy classes is not as much of a problem as the ability to retain them until graduation. First generation and low-income college students, especially, are at risk of dropping out. This partly sparked the leadership's desire to have a mentoring program to improve the educational and social experience of students, and to help keep them enrolled until completion. The Initiative's leadership believed that mentoring relationships, especially 
those that develop naturally, may be a productive way of addressing the college adjustment issues that at-risk students face (Thile \& Matt, 1995).

Santos and Reigadas (2002) attest that "a quality faculty-student mentoring relationship is likely to engender positive self-perceptions in at-risk students as well as feelings of self-efficacy, personal control, respect for oneself, and a sense of being valued and respected by significant others" (p. 42). It is also theorized that when mentors and mentees share common viewpoints by way of similar ethnic or cultural backgrounds, it creates a sense of homogeneity in the relationship and may enhance supportiveness - a quality that is critical in the life of young adults (Tinto, 1987). Thompson (1995) adds that this dimension of the mentor-mentee relationship, in which participants in the mentoring program share common attributes such as occupational goals, religious values, and cultural background, offers more positive perspectives on life and fosters emotional support (p. 44).

The Initiative's leadership felt that mentors could provide advice and guidance to the young men on how to chart their life's course as students and as graduates who would leave to pursue profitable future endeavors. They hoped that the associated Program would serve as a platform for community building and networking among its participants, and would assure the students that they had advocates on campus - people on whom they could rely for better academic and career decisions. The leadership anticipated that the programmatic activities would help the students develop quality leadership skills that would position them socially as equally accepted contributors of national development, with equal rights and responsibilities (Interview with the Program leadership, 2013).

\section{METHOD}

The evaluators first decided to employ the term "African American" to describe the portion of the research population who were of African descent. When reviewing the administrators' interview transcripts, however, the evaluators found that one of the adminstrators primarily employed the term "Black" when referring to the students of African descent who took part in the Initiative. The other administrator used the term "African American" to describe this part of the research population. Although individuals who identify themselves either as African American or as Black may participate in this Initiative, the evaluators chose to employ the term "African American" as it is more representative of the Program participants and, specifically, of the respondents who were interviewed. For this article, the evaluators have also de-identified all respondents and present just the views of the respondents about the Initiative and the Program.

\subsection{Sampling}

Given the young age of the Initiative and its associated Program, three years and four months respectively, and that both were still in a developmental stage, the researchers conducted a formative evaluation (Division of Research, Evaluation and Communication, and National Science Foundation, 2002, p. 8). The researchers used interview protocols with relevant stakeholders to understand more about the Initiative and the Program. The interview data was then treated using qualitative data analysis such as coding themes (e.g., Coffey \& Atkinson, 1996) both within each and across all stakeholder interviews. The decision to use interview protocols for data collection and a qualitative approach to data analysis stemmed from the researchers' employment of the transactional model (House, 1978; Patton, 2002; Rippey, 1973; Stake, 1973), discussed further below. This model is based upon gathering the different perspectives of the various stakeholders involved in the evaluated program (in this case the Initiative and its associated Program). In light of the nature of this model, the researchers chose for the evaluation design to use maximal variation sampling, which is a purposeful sampling strategy (Creswell \& Clark, 2011, pp. 173-174; Teddlie \& Yu, 2007). 
According to Creswell and Clark (2011), purposeful sampling is when "researchers intentionally select...participants who have experienced the central phenomenon...explored in the study" (p. 173). In maximal variation sampling, "diverse individuals are chosen who are expected to hold different perspectives on the central phenomenon" (p. 174). The evaluators chose the purposive sampling approach, for which fewer than 30 respondents are typically selected for the "narrative data" gathering process (Teddlie \& Yu, 2007, p. 84). The evaluators interviewed the only two administrators of the Initiative and Program, and had originally planned to interview the 42 Program participants (21 student mentees and 21 volunteer mentors). Time, however, did not permit this as the evaluators had hoped. Hence, due to the time limitations, they were only able to interview four students and two mentors.

\subsection{Instrumentation and Data Collection}

The evaluators developed and used three different interview protocols for the various stakeholders, stemming from the employment of the transactional evaluation model (House, 1978). They used notes taken from separate meetings with an OID representative and with the Initiative's leadership to understand more about the Initiative's establishment, as well as its past and present programmatic activities. The evaluators gathered additional background information by observing the interactions between the administrators and the students. To allow access to information on the Program's activities, the Initiative's leadership added the evaluators to the Program mailing list. The evaluators attended the Program's monthly meeting as "observers as participants" (Glesne, 2006, p. 50) in order to have first-hand experience with the student activities. Glesne (2006) supports this notion explaining that, "the researcher remains primarily an observer but has some interaction with study participants" (p. 50). This interaction helped evaluators to build rapport with Initiative members.

Attending the initial meetings with administrators and two monthly Program group meetings with the students allowed the evaluators to obtain data about issues of importance to the students, the topics discussed at focus groups, the students' personal and professional goals, and their future plans (e.g., summer internships). The evaluators used this data, along with related literature, to develop the interview protocols. The evaluators interviewed respondents to gain insight into their differing perspectives on the Initiative and its associated Program. The interview data helped the researchers to meet their two evaluation objectives, stated above, as participants freely expressed their perceptions about the Initiative and the Program's activities. The researchers were allowed to audio-record each interview, and to take notes to supplement the recordings, which were then transcribed for thematic analysis.

Not only did the evaluators seek to understand the Initiative's goal(s) and stakeholders' satisfaction or dissatisfaction with it, they also wanted to understand these aspects with regard to the Program, given its intimate connection with the Initiative. The evaluators discovered some connection after establishing their evaluation objectives in the process of conducting their early research into the background of the Initiative. They, however, maintained these objectives and decided to seek additional information during the interviews to clarify the connection between the two efforts. Thus, they present findings related to both the Initiative and the Program in this report.

\subsection{Analysis and Interpretation}

Data analysis began with transcription of the interviews. The evaluators then employed thematic analysis, which first involves coding the data and then grouping those codes (Coffey \& Atkinson, 1996). Mishler (2003) explains that the theoretical framework and methodology underlying a study affects how researchers choose to present the text in their transcriptions and in the conclusions drawn from their findings. Indeed, when the evaluators transcribed and coded the text of their respective interviews, they made certain decisions based upon the specific issues 
and theoretical foundations at work in the evaluation. As a result, the evaluators recognize that their particular perspectives from researching this topic influenced the codes they established as a group and individually, how they coded the text, and the quotes they chose to present in their findings.

To begin the data analysis process, the evaluators established initial codes, or categories, for use in the analysis of each interview based on the two evaluation objectives, the overall research question, and the literature review (Coffey \& Atkinson, 1996). Since they needed to understand the stakeholders' perspectives on the goal(s) of and satisfaction or dissatisfaction with the Initiative and its associated Program, the evaluators created codes that reflected these objectives. The initial code of "goal" accounted for text sections that included words such as goals, purpose, and intentions. The initial codes of "satisfaction" and "dissatisfaction" accounted for text sections that included words such as expectations, direction, value, and future involvement.

The evaluators coded for their respective interviews using the initial codes, while also allowing for additional codes to emerge from the interview data (i.e., in vivo codes) (Strauss, 1987, as cited in Coffey \& Atkinson, 1996, p. 32). To begin identifying themes across the interviews, each evaluator presented the codes used in his or her given interview, both initial and in vivo, to determine if any of the other interviews had similar categories. The evaluators, therefore, maintained the integrity of the individual stakeholders' viewpoints by allowing unique codes to arise from each interview's content. They then compared each interview's distinctive codes to see if any of them conceptually aligned. If they did, the evaluators combined them to produce a new category that was then added to the list of existing categories.

Each of the interviews was then color-coded and segments of text from each interview were placed under the relevant coding category or categories. The evaluators finally grouped the categories and their matching textual data techniques such as developing codes to identify themes (Coffey \& Atkinson, 1996). From these themes, the evaluators fulfilled the two evaluation objectives by identifying how each of the interviewed stakeholders understood the goal(s) of the Initiative and the Program (Objective \#1), and whether or not they were satisfied with the two endeavors thus far (Objective \#2). Thematic analysis of the in vivo codes from each interview helped the evaluators to address the overall evaluation question of whether stakeholders viewed the Initiative (and its associated Program) differently from other stakeholders (House, 1978). At times, the evaluators found sections of text that did not fit within their existing coding categories. Hence, they labeled them as "outliers" and considered them valuable data worthy of additional analysis (Coffey \& Atkinson, 1996, p. 47).

\section{FINDINGS}

Quotations from the stakeholders describing their viewpoints on the Initiative and Program goal(s) can be found in Tables 1 and 2, respectively. Stakeholder quotations relaying satisfaction or dissatisfaction with the Initiative and Program can then be found in Tables 3 and 4, respectively. Upon analyzing the interview data, the evaluators found that the stakeholders' views were similar, yet different in the ways in which they were expressed.

Although the evaluators entered the interview with Administrator \#1 [Initiative and Program Director] with the idea that the goals of these two efforts would be somewhat related, they left with the knowledge that the purposes were basically one and the same. 
Table 1. Stakeholders' Perspectives on Initiative's Goal (Evaluation Objective \#1)

\begin{tabular}{|c|c|c|c|}
\hline Administrator \#1 & Administrator \#2 & Mentor & Student \\
\hline $\begin{array}{l}\text { "Improve the experience the } \\
\text { Black and Latino males have } \\
\text { on this campus, educational } \\
\text { experience, social experience" } \\
\text { "Improve that experience for } \\
\text { them to increase retention } \\
\text { rates of Black and Latino } \\
\text { males on campus and to } \\
\text { increase graduation rates of } \\
\text { Black and Latino males" } \\
\text { "To prepare them to leave here } \\
\text { to lead successful lives, (i.e., } \\
\text { going to graduate school and } \\
\text { finding success in professional } \\
\text { school, careers, families)" } \\
\text { "Help them to find success } \\
\text { once they leave and to live up } \\
\text { to what their potential is" }\end{array}$ & $\begin{array}{l}\text { "To turn out educated } \\
\text { men who are making a } \\
\text { contribution to the } \\
\text { betterment of society" } \\
\text { "An acceptance of Black } \\
\text { and Latino males for } \\
\text { who they are...Black } \\
\text { and Latino males will } \\
\text { come to be respected... } \\
\text { That there will no } \\
\text { longer be } \\
\text { the demand that they } \\
\text { should explain why } \\
\text { they're here..." }\end{array}$ & $\begin{array}{l}\text { "The goal was to provide } \\
\text { these young men forums } \\
\text { and situations and with } \\
\text { individuals that they can } \\
\text { talk to, that they can } \\
\text { converse with..." } \\
\text { "We're trying to give } \\
\text { them an opportunity to } \\
\text { talk about some of the } \\
\text { issues that they face and } \\
\text { trying to give them } \\
\text { sounding boards in us to } \\
\text { where we can say, 'Yeah, } \\
\text { we get it. We had the } \\
\text { same thing happen to us } \\
5,10, \\
15,20,30, \text { ' however old } \\
\text { you are, 'years ago'" }\end{array}$ & $\begin{array}{l}\text { "To like hook us up with like } \\
\text { mentors and leaders" } \\
\text { "To address problems on } \\
\text { campus specific to PSEU's } \\
\text { campus and to try to like see } \\
\text { how we can work on them" } \\
\text { "To just promote diversity on } \\
\text { campus" } \\
\text { "To connect us with the } \\
\text { resources since we are the } \\
\text { minorities on campus, so that } \\
\text { we don't feel excluded in } \\
\text { anything" } \\
\text { "And yeah, like the } \\
\text { graduation factor. Having } \\
\text { somebody be accountable for } \\
\text { you, so that you don't just } \\
\text { come here and fail out of } \\
\text { college. It's like an } \\
\text { intervention tool" } \\
\text { "And to just unite Blacks and } \\
\text { Latinos because our } \\
\text { populations on campus are so } \\
\text { small" }\end{array}$ \\
\hline
\end{tabular}

Reflecting on the involvement with the Initiative or Program, Administrator \#1 described the experience as being "very similar to my initial expectations... you know, at this point we don't have any support from the university by way of staff or help or finances or anything like that, and so I guess my expectations were pretty in line with what the reality would become." This administrator expected it to be "possible for these young men to be successful," but foresaw a difficult situation because of a lack support from the PSEU. He or she was, however, pleased with the level of commitment from the student participants, volunteer mentors, and other stakeholders involved with the Program, and that the young men were establishing good relationships with their mentors.

Administrator \#1 also admonished that,

If you want a program to be successful you have to make it somebody's job. Even if it's not their full-time job.... and that takes money. That takes staff.... [A]nd so we have no investment in it right now." With part-time or full-time staff to help with coordination, this administrator believes the Initiative would "be further along in terms of building out the Program, building out structures, building out curriculum, so that those things we can produce and put on the shelf and be able to use for years to come.

But, the administrator acknowledges that, "the support for this kind of work needs to come from somewhere. Because when you [look] at institutional research and you look at where Black men are, and where Latino men are, I mean the need is clear as day." This administrator was of the view that, "There are funds available for this type of work. There are a lot of grants out there that fund this type of work...the problem is, it has to be somebody's job, and somebody has to have the time to write grants and go out there and go after the money." 
Table 2. Stakeholders' Perspectives on Program's Goal (Cont. Evaluation Objective \#1)

\begin{tabular}{|c|c|c|c|}
\hline Administrator \#1 & Administrator \#2 & Mentor & Student \\
\hline $\begin{array}{l}\text { Insinuates during the } \\
\text { interview that the goals of } \\
\text { the Program and the } \\
\text { Initiative are the same. }\end{array}$ & $\begin{array}{l}\text { "Even though it's a program } \\
\text { to help build the success of } \\
\text { our underrepresented young } \\
\text { men, it is, in fact, a research } \\
\text { project, because hopefully } \\
\text { what we learn will be useful } \\
\text { to somebody else" } \\
\text { "When we incrementally } \\
\text { grow the resources } \\
\text { [described in Findings] ... } \\
\text { [the Program's goals will be] } \\
\text { to provide these young men } \\
\text { with the kinds of experiences } \\
\text { that I have described. To see } \\
\text { them leave PSEU with the } \\
\text { confidence and the } \\
\text { knowledge about their place } \\
\text { in and their interaction with } \\
\text { the world. And that they } \\
\text { would take that and } \\
\text { encourage more men, } \\
\text { generation after generation, } \\
\text { every young boy that they } \\
\text { meet, all the men involved in } \\
\text { their lives, that they would } \\
\text { just pay it forward" }\end{array}$ & $\begin{array}{l}\text { "I think the goal for the } \\
\text { program is just to make } \\
\text { the...I know early on, [an } \\
\text { administrator] motivated it } \\
\text { by talking a little bit about } \\
\text { graduation rates and trying } \\
\text { to increase the retention of } \\
\text { Black males on campus. I } \\
\text { think, though, that the way } \\
\text { that the Program can be } \\
\text { really valuable is just that if } \\
\text { we see ourselves as trying to } \\
\text { make the experience of } \\
\text { being a Black male here at } \\
\text { PSEU just a little bit easier } \\
\text { for them" }\end{array}$ & $\begin{array}{l}\text { "I'll just say the goal is just to } \\
\text { have us graduate from PSEU } \\
\text { and just give us like a safe } \\
\text { haven for us, you know" } \\
\text { "Just to promote our } \\
\text { scholarship, our awareness of } \\
\text { what's going on in the } \\
\text { African, Black community" } \\
\text { "Just help, just promote us to } \\
\text { do positive things on campus. } \\
\text { The older guys are just } \\
\text { looking out for us 'cuz it will } \\
\text { help us in the future" }\end{array}$ \\
\hline
\end{tabular}

Administrator \#2 stated that the motivation for starting and staying involved with the Initiative stemmed from years of experience working in higher learning institutions in different parts of the country, and seeing the same issues with the success of African American and Latino male students at all of these various institutions. This administrator shared:

Being in America where - let's face it, I'm not naïve about it, and I hope you're not where racism is still alive and well, ... racial understanding is yet to reach the depths that they should, in order for us, together, to move this country forward. It sounds terribly idealistic, and I am an idealistic person, but I'm also very realistic and practical. I know that there are things you've got to come to grips with on the ground before you can get those dreams in the sky.

Administrator \#2's initial involvement the Initiative stemmed from the desire to put something in place at the PSEU that would help African American and Latino students to achieve, even when there are barriers preventing them from doing so. He or she also served as a mentor to one of the young men in the Program at the time of this evaluation. As for future involvement with the Initiative, Administrator \#2 planned to continue to "serve as a mentor for as many of the young men who appreciate that." He or she also had several expectations upon developing this Initiative, but anticipated that the endeavor would yield gradual results. Administrator \#2 explained:

They've [Initiative and Program leadership] only just begun. These things take time. Few people appreciate that growing diversity and strengthening inclusion is a process, and people can be so impatient. And ... this situation has been decades in the making - how do you expect somebody to fix it overnight?

Furthermore, the administrator shared that what is being done within the Initiative is "endless work" and that "there can never be an end date." 
Table 3. Stakeholders' Satisfaction/Dissatisfaction with Initiative (Evaluation Objective \#2)

\begin{tabular}{|c|c|c|c|}
\hline Administrator \#1 & Administrator \#2 & Mentor & Student \\
\hline $\begin{array}{l}\text { Satisfaction: "I think the } \\
\text { community building is very } \\
\text { important among [the students] } \\
\text { themselves and I see evidence } \\
\text { of that.... [the] relationships } \\
\text { that I have developed with } \\
\text { them are important. And so, } \\
\text { it's now more common than } \\
\text { [in] the beginning of the year } \\
\text { for me to get a phone call or } \\
\text { email for somebody to stop by } \\
\text { and talk about something or an } \\
\text { idea, and that's important" }\end{array}$ & $\begin{array}{l}\text { Satisfaction: "It's not about } \\
\text { satisfaction. Like I said, } \\
\text { there is no end date. You } \\
\text { can never be satisfied, } \\
\text { because there's always } \\
\text { something to be done, } \\
\text { something that needs to be } \\
\text { done, something that should } \\
\text { be done. There's always } \\
\text { something that needs to be } \\
\text { undone, because we're } \\
\text { dealing with humans and } \\
\text { we're not perfect" } \\
\text { Dissatisfaction: "And we're } \\
\text { always grappling with our } \\
\text { beliefs, and having the } \\
\text { courage (or not) to } \\
\text { interrogate those beliefs (or } \\
\text { not), so it's a dynamic } \\
\text { situation. So no, I'm not } \\
\text { satisfied. I'll never be } \\
\text { satisfied" }\end{array}$ & $\begin{array}{l}\text { Satisfaction: "No problem... } \\
\text { I'm pretty satisfied" } \\
\text { Satisfaction: "I think the } \\
\text { idea is great. . I think that } \\
\text { the effort that Dr. is } \\
\text { putting into it and that the } \\
\text { other administrators are } \\
\text { putting into it is a genuine } \\
\text { thing and it's something that } \\
\text { is needed" } \\
\text { Dissatisfaction: "If there } \\
\text { was any dissatisfaction on } \\
\text { my part, it would be on my } \\
\text { own doing. It's not having } \\
\text { been able to make it to a } \\
\text { couple of the meetings, the } \\
\text { full meetings that they've } \\
\text { had with the group ... but } \\
\text { that's all, that's on me. That } \\
\text { has nothing to do with the } \\
\text { In it i a ti ve itself" }\end{array}$ & $\begin{array}{l}\text { Satisfaction: "It has } \\
\text { allowed me to meet some } \\
\text { people and has given me } \\
\text { something to be proud that } \\
\text { I am a part of on PSEU's } \\
\text { campus as far as something } \\
\text { that affects the diversity } \\
\text { initiative that the school } \\
\text { promotes. It makes me feel } \\
\text { like I'm being an active } \\
\text { participant in that" } \\
\text { Satisfaction: "And it makes } \\
\text { me feel like my school is } \\
\text { providing an opportunity to } \\
\text { help me, I guess" } \\
\text { Satisfaction: "Just have } \\
\text { somebody that is similar to } \\
\text { me that I can identify with } \\
\text { so that I don't feel singled } \\
\text { out on campus or anything. } \\
\text { And it helps me connect } \\
\text { with faculty that are like } \\
\text { African American who are } \\
\text { in higher positions on } \\
\text { PSEU's campus and you } \\
\text { know feel more } \\
\text { comfortable during my stay } \\
\text { here so, yeah" }\end{array}$ \\
\hline
\end{tabular}

As for ideas about improving the Program, Administrator \#2 shared that everything could always be done better, but what is most crucial is "engaging it at the proper time and under the proper circumstances." He or she stated that for now "it works" in regard to the Program's activities and the leadership's efforts at the time of the evaluation. But in the future, Administrator \#2 hoped to recruit the assistance of a psychologist or a psychiatrist to help the young men involved in the Initiative to deal with the issue of self-efficacy. Tutors could also help the students with concept mastery, and engage them in discussions about literature and art as well as the connections between the two. He or she stressed that the young men could also benefit from assistance in planning trips abroad as a way to encourage them to connect with young men worldwide and to learn about the issues they face.

From the volunteer mentor's perspective, the Program could reach out to other students who may not be as motivated to succeed in school. This would address the issue of retention of African American and Latino men. He explained his thoughts as follows:

I think the mentees had to apply and it was a pretty selective process [into the Program]. Part of me wonders if those are the students that needed help, anyway, you know? I wonder if there would be some kind of way that we could touch those students that didn't sign up because those are probably the ones who were more likely not going to maybe have the skills that they need, the prerequisite skills to come into a big campus like this and perform academically. That's not necessarily the program's fault. I understand from the perspective of the program you're kind of taking those very talented young men [and] giving them extra resources, so that they can go back and lead others.

Aside from these few recommendations, this mentor was both positive and encouraging about his experience with the Initiative and the Program. He praised the work the administrators were 
doing to support this program, and also highlighted the intelligence and the potential of the student participants. He said he was pleased to be a part of this effort.

Table 4. Stakeholders' Satisfaction/Dissatisfaction with Program (Cont. Evaluation Objective \#2)

\begin{tabular}{|c|c|c|c|}
\hline Administrator \#1 & Administrator \#2 & Mentor & Student \\
\hline $\begin{array}{l}\text { Satisfaction: "...the } \\
\text { relationships they are building } \\
\text { with their mentors, those are } \\
\text { important because they're } \\
\text { getting the same messages over } \\
\text { and over again" } \\
\text { Satisfaction: "And, they know } \\
\text { that they have people that they } \\
\text { can go to with any problem. } \\
\text { So, I think we're helping" } \\
\text { Dissatisfaction: "Would I go } \\
\text { so far to say [what] we're } \\
\text { doing is now increasing } \\
\text { retention and graduation rates? } \\
\text { No, I can't say that" } \\
\text { Dissatisfaction: "Absolutely } \\
\text { not. To be honest, I am less } \\
\text { than satisfied. I'm really } \\
\text { ashamed of what we have here. } \\
\text { I mean, the only thing we've } \\
\text { been able to build with, } \\
\text { specifically, the Program is } \\
\text { what I pull out of my extra } \\
\text { time, you know after dealing } \\
\text { with teaching and writing and } \\
\text { other responsibilities. That's } \\
\text { not the way to build a program } \\
\text { or run a program. So, I'm not } \\
\text { satisfied. I'm much more } \\
\text { ashamed than satisfied with } \\
\text { what we've done" }\end{array}$ & $\begin{array}{l}\text { Satisfaction: "Well, again, } \\
\text { under the circumstances, I } \\
\text { think that we're going in the } \\
\text { best direction that we can" } \\
\text { Dissatisfaction: "Because we } \\
\text { don't have endless money to } \\
\text { put into this, to bring in some } \\
\text { of the kinds of people that I } \\
\text { talked about, to have the } \\
\text { sessions that I talked about" }\end{array}$ & $\begin{array}{l}\text { Satisfaction: "Yeah, I'm } \\
\text { pretty satisfied with it. And } \\
\text { so ... you know, you just } \\
\text { kind of get to know them a } \\
\text { little bit. Get to know their } \\
\text { [students'] personality. I } \\
\text { would anticipate, } \\
\text { hopefully, in the next } \\
\text { couple of meetings and } \\
\text { things like that, as things } \\
\text { start to progress a little bit, } \\
\text { you know, we may get into } \\
\text { other issues that's he's } \\
\text { having, academically or } \\
\text { whatever" }\end{array}$ & $\begin{array}{l}\text { Satisfaction: "But I would } \\
\text { say the group discussion is } \\
\text { the most important. } \\
\text { And just the goal setting, } \\
\text { and helping us keep in mind } \\
\text { our goals" } \\
\text { Satisfaction: "Really } \\
\text { satisfied. I liked the } \\
\text { induction ceremony. That } \\
\text { was a really good } \\
\text { experience" } \\
\text { Satisfaction: "Oh, with just } \\
\text { the discussions we have and } \\
\text { just the accountability } \\
\text { factor of having other } \\
\text { people that want you to } \\
\text { succeed and the opportunity } \\
\text { like if you, like it's a } \\
\text { program where like from } \\
\text { the beginning I felt that we } \\
\text { had ownership of it" } \\
\text { Satisfaction: "So far, yeah, } \\
\text { except for the service part } \\
\text { [which hadn't started yet] } \\
\text { like I said before. . I think } \\
\text { we guys are getting } \\
\text { something out of it, you } \\
\text { know. It may not be like } \\
\text { life changing on that scale } \\
\text { yet, but we are making } \\
\text { connections with our } \\
\text { mentors. So, I think so far it } \\
\text { is [has been positive]" }\end{array}$ \\
\hline
\end{tabular}

A student described his overall experience with the Initiative and the Program as positive. He alluded to the fact that he enjoyed the autonomy that the Program gave the students, as he explained...

I had ideas over winter break that I bounced off [Administrator \#1] and [Graduate Assistant]. And they were actually like, "Great idea man, we'll do it." Like one of the discussion topics [sic] at our first meeting was the Django movie and I had had an idea to do that. And so, he let me do the background research to kind of help facilitate the discussion. So, I was like "yeah!" It was a way for me to get more involved in it, and not just sit there and have them talk to me for like two hours. So, I just like the ownership that they let us take over what we learn and what we do in the Program.

He did make a couple of recommendations, such as holding meetings every week on different days, instead of only once a month on Mondays. He also suggested going on various fun outings, like to movies and horse races. 


\section{DISCUSSION and RECOMMENDATIONS}

Even considering the limitations of time constraint and small sample size, the study provides a strong contribution to the literature. The utility of this evaluation is in the in-depth examination of the programmatic development process, qualitative data analysis, and application of evaluation methods. Additional utility can be derived from the subject matter of this evaluation as it illustrates procedures PWIs have taken to address diversity and retention issues on campus.

Although the evaluators were unable to each individually code all the interviews to help ensure inter-coder reliability, the team did prescribe agreed-upon codes and resulting coding categories based upon their experience with the evaluation and their review of the literature. Furthermore, at least two evaluators attended each transcribed interview, supporting validity as they were familiar with the content of each of the four transcribed interviews. This inter-rater check also served to strengthen reliability. At the onset, there was some confusion on the evaluators' part as to whether the Initiative or the Program was the unit of analysis. This concern quickly dissolved, as the team understood that while these endeavors were separate in name, their intended goals were tightly linked. The Initiative served as the umbrella under which the Program and the ongoing dialogue session resided.

Ideally, the evaluators would have field-tested the instruments with stakeholder groups involved in similar programming at other institutions prior to employing them in this evaluation. Furthermore, time constraints prevented evaluators from following up with interviewees to obtain additional information and clarification of initial responses; to hold a focus group session for student participants; and to conduct more interviews, which would have provided a broader collection of viewpoints and descriptions of the Initiative and its Program.

The overarching question for the researchers was to find out how various stakeholders see the Initiative from their vantage points. The stakeholders' responses indicated that the Program was born out of the Initiative, and exists to help achieve the overall goals of the Initiative. Thus, future researchers should endeavor to see the two seemingly different efforts as such. Meaning, activities of the Program should be assessed in light of how they impact the goals of the Initiative. Furthermore, even though they expressed it in different ways, the interviewed stakeholders recognized the Initiative as an effort to improve the campus experiences of minority students. To quote from the tables above, a student participant said,

... it was gonna be something that, I don't know, I just really have a genuine interest in and I just wanted to get more, you know, connected with other African American male college students just, you know, to create more relationships and bonds on campus, just because I wasn't really involved in anything that directly connected me to like a diversity type thing. And just being at a school where African Americans are the minority, it's just another opportunity to do something positive, I guess, with people I can more readily identify with.

Another said, "And yeah, like the graduation factor. Having somebody be accountable for you, so that you don't just come here and fail out of college. It's like an intervention tool." The student added the Initiative was to help "... connect us with the resources since we are the minorities on campus, so that we don't feel excluded in anything." A mentor stated that one of the goals of the Initiative "... was to provide these young men forums and situations and with individuals that they can talk to, that they can converse with..." about the issues they face as they strive to graduate. The stakeholders' views were in line with the Initiative's goals of improving racial diversity, campus experiences of minority students, their graduation rates, among others, indicating that administrators had been effective in communicating the goals of the Initiative to its stakeholders. 
One of the objevtices of the researchers was to determine if the student participants, administrators, and volunteer mentors were satisfied thus far with the Initiative. In response to this question, a student participant said,

So I was afraid that this might be something that would be a little bit too much as far as the requirements for like, hours mentoring and different things. But then as I got into it, I figured out that like ... the coordinators were more trying to see what we wanted to do and what we wanted to talk about instead of just giving us a bunch of work and time commitments to do, so I really like that aspect of it. They're really just trying to be like a guidance and more of a help to us than pretty much being like army sergeants to boss us around... I really enjoyed the program so far.

Another student participant stated, "[The Program] has allowed me to meet some people and has given me something to be proud that I am a part of on PSEU's campus as far as something that affects the diversity initiative that the school promotes. It makes me feel like I'm being an active participant in that." The student participant added, "Just to have somebody that is similar to me that I can identify with so that I don't feel singled out on campus or anything. And it helps me connect with faculty that are like African Americans who are in higher positions on PSEU's campus and you know, feel more comfortable during my stay here so, yeah." One mentor said, "I think the idea is great. . . I think that the effort that ... administrators are putting into it is a genuine thing and it's something that is needed." The mentor also said, so far "No problem ... I'm pretty satisfied." Such responses gave indications that the initial general goal of the Initiative, which focused efforts on providing a place for this particular group of students to discuss their campus experiences, was being achieved. The mentors and student participants were satisfied thus far with the Initiative's trajectory.

At the time of this evaluation, the Initiative, through its Program activities, had already proven beneficial for students involved; however, a lack of resources impeded the realization of all the goals set forth by the Initiative's leadership. From the analysis of the interview data, it appeared that the PSEU neither fully appreciated nor supplied the support required by the Initiative to continue and grow the efforts that are so urgently needed to encourage and retain the African American and Latino men involved in these endeavors. The Initiative is in need of resourcesprogram coordinators and money. There is a need for a designated individual (preferably a paid position) to carry out the ongoing and planned programming activities, instead of faculty members shouldering this responsibility in addition to their regular duties. Indeed, greater PSEU involvement, such as increased promotion and funding of the Initiative's activities, could help bolster the credibility and acceptance of the overall Initiative. Witnessing such PSEU involvement has the potential to encourage more people to participate in the Initiative, which could in turn help improve retention among minority students at the university.

In sum, the evaluators set out to evaluate the Initiative and the Program, which had been modeled, although a modified version, after the BMIs of a nearby PSEU and that of another institution on the east coast. The responses of the stakeholders indicated that the two efforts did not have different goals, rather the Program was an offshoot of the Initiative and its activities were meant to help achieve the goals of the Initiative. The overarching goal of the Initiative was to improve the campus experiences of students of color at the PSEU, and the interviewed stakeholders believed the Initiative was moving in the right direction and achieving its goals. The negative takeaway was the bemoanment of the failure of the institution to recognize the need to make resources available for the Initiative to thrive. Too often in education, proper funding of initiatives is the reason goals are not met or programs do not reach their full potential. This Initiative is an example of an action response to the difficulties African American and Latino male populations are facing at higher education institutions across the country and, based 
on the preliminary evaluation, should be supported by the institution and considered by others dealing with similar issues.

\section{ORCID}

Kelly D. Bradley (D) http://orcid.org/0000-0002-4682-8212

\section{REFERENCES}

Coffey, A., \& Atkinson, P. (1996). Concepts and coding. In Making sense of qualitative data: Complementing research strategies, pp. 26-53. SAGE Publications: Thousand Oaks, CA.

CUNY Black Male Initiative. (2005). http://www1.cuny.edu/sites/bmi/wpcontent/uploads/sites/24/page-assets/about/CUNY_BMI_Overview.pdf

Ford, D. Y. (2012). Culturally different students in special education: Looking backward to move forward. Exceptional Children, 78(4), 391-405.

Glesne, C. (2006). Being there: Developing understanding through participant observation. In Becoming qualitative evaluators: An introduction (3rd Ed.), pp. 49-78. Pearson Educational: New York, NY.

Gurin, P., Dey, E., Hurtado, S., \& Gurin, G. (2002). Diversity and education: Theory and impact on educational outcomes. Harvard Educational Review, 72(3), 330-366.

House, E. R. (1978). Assumptions underlying evaluation models. Educational Researcher, 7(3), 4-12.

Initiative Leadership at PSEU. (2013-01-22). Electronic mailing list message. Male Scholars Mentoring Program.

Jackson, B. A. (2012). Bonds of brotherhood: Emotional and social support among college Black men. The ANNALS of the American Academy of Political and Social Science, 642(1), 61-71. doi: 10.1177/0002716212438204.

Jones, L., Castellanos, J., \& Cole, D. (2002). Examining the ethnic minority student experience at predominantly White institutions: A case study. Journal of Hispanic Higher Education, 1(1), 19-39.

Kim, M. M., \& Conrad, C. F. (2006). The impact of historically Black colleges and universities on the academic success of African-American students. Research in Higher Education, 47(4), 399-427.

Lascher, E. L. (2008). Retaining Latino and non-Latino college students: Key similarities and differences. A report for the Serna Center and the Institute of Higher Education Leadership and Policy, http://www.csus.edu/sernacenter/assets/publications/retention.pd f. Accessed March 06, 2013.

Lewis, W. D., Oliver, S. T, \& Burris, J. L. (2011). A work in progress: The lived experiences of Black male undergraduates at one predominantly White university. Kentucky Journal of Higher Education Policy and Practice, 1(1), 1-30.

McGee, E. B., \& Martin, D. B. (2011). You would not believe what I have to go through to prove my intellectual value! Stereotype management among academically successful Black mathematics and engineering students. American Educational Research Journal, 48(6), 1347-89. doi: 10.3102/0002831211423972.

Mishler, E. G. (2003). Representing discourse: The rhetoric of transcription. In Lincoln Y. \& Denzin N. (eds.), Turning Points in Qualitative Research: Tying Knots in a Handkerchief, pp. 297-326. Alta Mira Press: Walnut Creek.

Office of Diversity and Inclusion-UCO. (2014). Black Male Initiative and Fellows Program. University of Central Oklahoma. http://sites.uco.edu/student-life/diversity/diversityinitiatives/black-male-initiative.asp 
Patton, M. Q. (2002). Qualitative Research and Evaluation Methods. Thousand Oaks, CA: Sage Publication.

PSEU public relations representative. Document found on PSEU's website (2012). Accessed March 15, 2013.

Redden, E. (2009, July 14). Reaching Black men. Inside Higher Education. Accessed March 6, 2013. http://www.insidehighered.com/news/2009/07/14/blackmale

Rippey, R. M. (1973). The nature of transactional evaluation. In Rippey R. M. (ed.), Studies in transactional evaluation, pp. 8-13. McCutchan Publishing Corporation: Berkeley, CA.

Roderick, M. (2003). What's happening to the boys? Early high school experiences and school outcomes among African American male adolescents in Chicago. Urban Education, 38(5), 538-607. doi: 10.1177/0042085903256221.

Santos, S. J., \& Reigadas, E. T. (2002). Latinos in higher education: An evaluation of a university faculty mentoring program. Journal of Hispanic Higher Education, 1(1), 4050.

Seidman, A. (2005). Minority student retention: Resources for practitioners. In Gaither, G H (ed.), Minority retention: What works?, pp. 7-24. Jossey-Bass: San Francisco, CA.

Spitzberg, I. J., \& Thorndike, V. V. (1992). Creating community on college campuses. State University of New York Press: Albany, NY.

Stake, R. E. (1973). Program evaluation, particularly responsive evaluation. New Trends in Evaluation, keynote presentation at a conference at the Institute of Education, Göteborg University, Gothenburg, Sweden, pp. 1 - 15. http://education.illinois.edu/circe/Publicatio ns/Responsive_Eval.pdf, accessed April 30, 2014.

Strayhorn, T. L. (2010). When race and gender collide: Social and cultural capital's influence on the academic achievement of African American and Latino males. The Review of Higher Education, 33(3), 307-332. doi: 10.1353/rhe.0.0147.

Teddlie, C., \& Yu, F. (2007). Mixed methods sampling: A typology with examples. Journal of Mixed Methods Research, 1(1), 77-100.

Thile, E. L., \& Matt, G. E. (1995). The ethnic mentor undergraduate program: A brief description and preliminary findings. Journal of Multicultural Counseling and Development, 23(2), 116-126.

Thompson, R. A. (1995). What is social support? In Preventing child maltreatment through social support: A critical analysis, pp. 43-65. Sage Publications: Thousand Oaks, CA. Tinto, V. (1987). Leaving college: Rethinking the causes and cures of student attrition. University of Chicago Press: Chicago, IL.

University System of Georgia's African - American Male Initiative. (2002). https://www.usg. edu/assets/aami/files/AAMIAssessmentBrochure.pdf 


\section{Appendix A}

Minority Male Student Success Initiative Administrator Interview Protocol:

(Administrators \#1 and \#2)

1. Could you please describe the establishment of the Minority Male Student Success Initiative?

2. How did you become involved in this Initiative, and what motivated you to become involved?

3. Please describe your expectations regarding your role as an administrator when you started working with this Initiative.

4. Please describe your experience with this Initiative so far. How are your Initiative experiences similar to or different from your initial expectations?

5. Is PSEU working in collaboration with other higher education institutions on this type of initiative? If so, please describe this collaboration.

6. If other institutions do have similar initiatives, can you describe those initiatives? Do they take the same form as the Initiative at PSEU? Can you please describe the institutions that house these initiatives.

7. If similar initiatives do exist at other institutions, are they called by the same or different names?

8. Would you say that you are satisfied or dissatisfied to this point with your experience with this Initiative? Why?

9. Would you say that you are satisfied or dissatisfied to this point with the direction of this Initiative? Why?

10. What aspect of the program do you think is the most successful at this point? What aspect do you think is the least successful?

11. What would you change, if anything, about this Initiative?

12. How do you see your future involvement with this Initiative?

13. How would you describe the goal of the Minority Male Student Success Initiative? Do you think that the Initiative is meeting that goal? Why or why not?

14. Could you please describe the establishment of the Program?

15. Are you involved with this program? Why or why not? If you are involved, please describe how.

16. (If the interviewee is actively involved with the Program) If you are involved with this program, please describe your working relationship with the young men involved in the program.

a.) Do you interact with them outside of the parameters of the program? If not, why not? If so, how often?

b.) What do you talk with them about?

17. If you are involved with this program, have you noticed any changes in the group of young men from meeting to meeting? If so, what types of changes have you noticed? To what would you attribute these changes?

18. What aspect of the program do you think is the most successful at this point? What aspect do you think is the least successful?

19. Would you say that you are satisfied or dissatisfied to this point with your experience in this program? Why?

20. Would you say that you are satisfied or dissatisfied to this point with the direction of this program? Why?

21. What would you change, if anything, about this program?

22. How would you describe the goal of the Program? Do you think that the program is meeting that goal? Why or why not?

23. How do you see your future involvement with this program? 


\section{Appendix B}

\section{Program Student Member Interview \\ Protocol:}

1. How did you learn about this program?

2. Why did you apply to this program?

3. Please describe your experience with the application process for this program.

4. Please describe your initial expectations when you joined this program.

5. Please describe your experience as a participant in this program. How are your program experiences similar to or different from your initial expectations? What, if anything, have you learned from participation in this program?

6. Please describe your experience with the mentoring relationship to this point.

a.) How often do you have contact with your mentor? Who usually initiates the contact?

b.) What is your primary form of communication with your mentor? Do you utilize other forms of communication?

c.) What are the main topics that you discuss with your mentor? How long do your mentoring meetings usually last?

7. How would you describe the characteristics of a good mentor? How would you describe a mentor's role?

8. How would you describe the goal for your mentoring relationship?

9. How would you define personal success? Academic success? Professional success?

10. How do those around you (family members, friends, acquaintances, classmates, etc.) feel about your attending PSEU?

11. What do you like and dislike about PSEU's campus? Why did you choose to attend PSEU?

12. Would you say that you have any personal and/or academic influences (positive or negative) off campus? If so, who or what are they?

13. Please describe your experience as a Black or Latino male here on campus and in your home community. Is there a difference between these experiences? If so, could you please explain?

14. How would you describe Black/Latino culture? If and how does this influence your academic identity?

15. In what ways, if any, has participation in this program affected your campus experience? Your academic experience? Your experience in your home community?

16. What aspect of the program do you think is the most successful at this point? What aspect do you think is the least successful?

17. What serves as motivation for you in your academic and career development?

18. What effect, if any, do you think this program could have on your future as a professional?

19. Do you spend time with other male students in this program outside of meetings or program activities? If not, why not? If so, what types of things do you do in your time together?

20. Would you describe yourself as satisfied or dissatisfied with this program? Why? What would you change, if anything, about this program?

21. How would you describe the goal of the Program? Do you think that the program is meeting that goal? Why or why not?

22. How would you describe the goal of the Minority Male Student Success Initiative? Do you think that the Initiative is meeting that goal? Why or why not?

23. How do you see your future involvement with the Program? Would you recommend this program to others?

24. What year are you in college?

25. How old are you? 


\section{Appendix C}

Program Volunteer Mentor Interview Protocol:

1. How did you learn about this program?

2. How did you become involved in this program, and what motivated you to become involved?

3. Please describe your expectations regarding your role as a mentor when you started working with this program.

4. Please describe your experience with this program so far. How are your program experiences similar to or different from your initial expectations?

5. How would you describe the characteristics of a good mentor? How would you describe a mentor's role?

6. Please describe your mentoring relationship with your mentee.

a.) Please describe a typical mentoring meeting. How long does it usually last?

b.) How often do you have contact with him?

c.) What is your primary form of communication? d.) Do you utilize other forms of communication?

7. What topics do you discuss with your mentee?

8. Have you noticed any changes in your mentee from meeting to meeting? If so, what types of changes have you noticed? To what would you attribute these changes?

9. How would you describe the goal for this mentoring relationship?

10. Would you say that you are satisfied or dissatisfied to this point with your involvement in this program? Why?

11. Would you say that you are satisfied or dissatisfied to this point with the mentoring aspect of this program? Why?

12. What would you change, if anything, about this program?

13. How would you describe the goal of the Program? Do you think that the program is meeting that goal? Why or why not?

14. How would you describe the goal of the Minority Male Student Success Initiative? Do you think that the Initiative is meeting that goal? Why or why not? 